ORIGINAL ARTICLE

\title{
Demographic study of leukaemia presenting within the first 3 months of life in the Northern Health Region of England
}

\author{
R P S Bajwa, R Skinner, K P Windebank, M M Reid
}

J Clin Pathol 2004;57:186-188. doi: 10.1136/icp.2003.12039

See end of article for authors' affiliations

.....................

Correspondence to: Dr M M Reid, Department of Haematology, Royal

Victoria Infirmary, Queen Victoria Road, Newcastle upon Tyne NE1 4LP, UK; Micheal.Reid@nuth. northy.nhs.uk

Accepted for publication 20 July 2003
Aims: To determine the incidence and outcome of congenital leukaemia.

Methods: Retrospective population based study of putative leukaemia arising during the first 3 months of life over an 18 year period within the Northern Health Region of England.

Results: Nine infants with putative leukaemia were identified. Five had acute leukaemia and four had transient myeloproliferative disorder (TMD). Trisomy 21, either as Down's syndrome or perhaps restricted to proliferating marrow cells, was present in all four infants with TMD. The incidence of congenital acute leukaemia was $8.6 / 10^{6}$ live births/year, but would be less than half this value if only patients presenting within 4 weeks of birth were counted. Remission was induced in three of the five patients with acute leukaemia. One patient, who presented at birth, remains well five years after diagnosis. All four patients with TMD survive.

Conclusions: Congenital leukaemia is very rare but is not inevitably fatal. Finding trisomy 21 in spontaneously dividing blood or bone marrow cells of an infant with putative acute leukaemia, particularly within 3 months of birth, should encourage a cautious clinical approach and suggests that the diagnosis might be TMD.

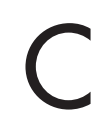

ongenital leukaemia is rare and usually diagnosed at birth or during the first several weeks of life. There are numerous case reports in the world literature, many in dermatological journals because of clinically prominent skin infiltration. Few studies of unselected series of cases have been published and variable age cutoff points have been used. Thus, its incidence is unclear and its reported behaviour may be affected by the selection bias intrinsic to individual case reports. Many case reports date back to an era when immunophenotypic and cytogenetic investigations were unavailable or only rarely used. In addition, transient myeloproliferative disorder (TMD), also known as transient abnormal myeloproliferation or transient myeloproliferative syndrome, has sometimes been confused with true acute leukaemia; the diagnosis of TMD can only convincingly be made in retrospect. The outcome for congenital leukaemia in published cases is typically poor, most patients dying with or without treatment. In contrast, TMD (as implied by its name) usually resolves spontaneously. There are no well established and generally accepted guidelines on the management of congenital leukaemia. However, approaches to the management of TMD, particularly in infants with Down's syndrome, are becoming more focused. ${ }^{1}$ We reviewed retrospectively our experience of putative congenital leukaemia in the Northern Health Region of England to reveal its incidence and outcome in an unselected, population based series.

"Congenital leukaemia is rare and usually diagnosed at birth or during the first several weeks of life"

\section{METHODS}

All children with suspected acute leukaemia in the Northern Health Region of England (excluding south Cumbria) are centrally referred for confirmation of diagnosis and management. They arise from a population of approximately 3.1 million, in which there were 628000 live births during the period October 1984 to September 2002. October 1984 was used as the start date because it coincided with the appointment of one of the authors (MMR). All children referred to the Paediatric Oncology Unit during that 18 year study period and diagnosed as having acute leukaemia or TMD within three months of birth were studied. Diagnoses were made on peripheral blood and/or bone marrow smears supplemented where possible by standard immunophenotypic and cytogenetic investigations.

\section{RESULTS}

Overall, nine infants presented with putative acute leukaemia. Table 1 shows their characteristics. Five were classed as having congenital acute leukaemia, four as TMD. They are ranked according to their dates of presentation. One patient presented in October 1984, eight between 1994 and 1999, and no case has been recognised since.

For those with true acute leukaemia the incidence was 8.6/ $10^{6}$ live births/year. Incidence rates for TMD have not been calculated because many cases with less obvious clinical features could have been undiagnosed and resolved spontaneously. In addition, the onset of TMD may occur well after the age limit of 3 months that we arbitrarily set for our study.

The five cases of acute leukaemia comprised a wide variation of biological subtypes, although common acute lymphoblastic leukaemia (ALL) was conspicuously absent. Patient 1 had acute myeloid leukaemia (AML) of myelomonocytic (M4) subtype and was the only patient with clinical skin involvement. Patient 2 had putative acute myeloid leukaemia (AML M7) based on postmortem histology, but with no immunophenotypic confirmation. Patients 5 and 9 had typical infantile null cell ALL associated with chromosome 1lq23 rearrangements. Patient 8 had unclassifiable acute leukaemia, either AML M0 or null cell ALL with positive myeloid markers. Patients 3, 4, 6, and 7, who were

Abbreviations: ALL, acute lymphoblastic leukaemia; AML, acute myeloid leukaemia; TMD, transient myeloproliferative disorder 
Table 1 Clinical features of children with congenital leukaemia and transient myeloproliferative disorder

\begin{tabular}{|c|c|c|c|c|c|c|c|c|c|c|c|}
\hline Patient & $\begin{array}{l}\text { Year of } \\
\text { diagnosis }\end{array}$ & $\begin{array}{l}\text { Age in } \\
\text { days } \\
\text { (sex) }\end{array}$ & $\begin{array}{l}\text { Clinical } \\
\text { phenotype }\end{array}$ & $\begin{array}{l}\text { Skin } \\
\text { involve- } \\
\text { ment }\end{array}$ & $\begin{array}{l}\text { White cell } \\
\text { count } \\
\times 10^{9} / \mathrm{I} \\
\text { (\% blasts) }\end{array}$ & $\begin{array}{l}\text { Bone } \\
\text { marrow } \\
\text { blasts (\%) }\end{array}$ & $\begin{array}{l}\text { Immunpheno- } \\
\text { type }\end{array}$ & Karyotype & $\begin{array}{l}\text { Specific } \\
\text { treatment }\end{array}$ & Outcome & Diagnosis \\
\hline 1 & 1984 & $42(F)$ & Normal & nodules & $66(7)$ & 30 & Not done & $46 X X$ & DAT & Died age 46 days & AML M4 \\
\hline 2 & 1994 & $0(F)$ & Down & No & $119(100)$ & Not done & Not done & Not done & None & Died age 1 day & AML M7 \\
\hline 3 & 1994 & $17(M)$ & Down & No & $9(2)$ & 12 & Not done & $47 X Y,+21$ & None & $\begin{array}{l}\text { Recovered } \\
\text { spontaneously }\end{array}$ & TMD \\
\hline 4 & 1995 & $0(M)$ & Normal & No & $39(90)$ & Not done & Not done & $\begin{array}{l}46 X Y 47 \\
X Y,+21\end{array}$ & None & $\begin{array}{l}\text { Recovered } \\
\text { spontaneously. No } \\
\text { features of Down's } \\
\text { syndrome }\end{array}$ & TMD \\
\hline 5 & 1996 & $88(F)$ & Normal & No & $50(100)$ & 95 & $\begin{array}{l}\text { CD19, HLADR, } \\
\text { TdT positive } \\
\text { CD10/13/33/ } \\
3 / 7 \text { negative }\end{array}$ & $\begin{array}{l}46 \times X \\
t(4 ; 11)\end{array}$ & $\begin{array}{l}\text { Infant ALL } \\
\text { regimen }\end{array}$ & $\begin{array}{l}\text { Remission } \\
\text { UD BMT } \\
\text { Relapse } \\
\text { Died age } 2 \text { years }\end{array}$ & Null ALL \\
\hline 6 & 1996 & $70(F)$ & Down & No & $6(1)$ & 15 & $\begin{array}{l}\text { CD13/33/ } \\
34 / 7 \text { positive } \\
\text { CD10/19/3, } \\
\text { TdT negative }\end{array}$ & $47 X X,+21$ & $\begin{array}{l}\text { None } \\
\text { DAT for } \\
\text { relapse }\end{array}$ & $\begin{array}{l}\text { Recovered } \\
\text { Relapsed AML } \\
\text { Remission } \\
\text { persists }\end{array}$ & $\begin{array}{l}\text { TMD } \\
\text { and } \\
\text { AML }\end{array}$ \\
\hline 7 & 1997 & $8(M)$ & Down & No & $90(100)$ & 90 & Not done & $\begin{array}{l}46 X Y \\
47 X Y,+21\end{array}$ & $\begin{array}{l}\text { Cytarabine } \\
5 \mathrm{mg} \\
\text { Cytarabine } \\
7.5 \mathrm{mg} \text { as } \\
\text { single doses }\end{array}$ & $\begin{array}{l}\text { Blast count fell } \\
\text { Complete recovery }\end{array}$ & TMD \\
\hline 8 & 1997 & 0 (F) & Normal & No & $354(100)$ & 90 & $\begin{array}{l}C D 13 / 33 \\
\text { positive } \\
C D 3 / 10 / 19 / 61 \\
\text { negative }\end{array}$ & $\begin{array}{l}46 X \\
\text { ins }(X ; 6)\end{array}$ & $\begin{array}{l}\text { Cytarabine } \\
7.5 \mathrm{mg} \\
\text { as single dose } \\
\text { Hybrid ALL and } \\
\text { AML regimen } \\
\text { UD BMT }\end{array}$ & $\begin{array}{l}\text { Remission } \\
\text { persists }\end{array}$ & $\begin{array}{l}\text { AML MO } \\
\text { ?Null ALL }\end{array}$ \\
\hline 9 & 1999 & $54(\mathrm{M})$ & Normal & No & $100(100)$ & Not done & $\begin{array}{l}\text { CD19 positive } \\
\text { CD10/3/13/ } \\
\text { 33, Tdt negative }\end{array}$ & $\begin{array}{l}46 X Y \\
+(11 ; 19)\end{array}$ & $\begin{array}{l}\text { Infant ALL } \\
\text { regimen }\end{array}$ & $\begin{array}{l}\text { Remission } \\
\text { RSV pneumonitis } \\
\text { Died age } 1 \text { year }\end{array}$ & Null ALL \\
\hline
\end{tabular}

ALL, acute lymphoblastic leukaemia; AML, acute myeloid leukaemia; DAT, daunorubicin, cytarabine, thioguanine; RSV, respiratory syncytial virus; TdT, terminal deoxynucleotidyl transferase; TMD, transient myeloproliferative disorder; UD BMT, unrelated donor bone marrow transplant.

diagnosed as having TMD, either had no bone marrow examination or had morphological features of myelodysplastic syndrome.

No treatment was offered to one infant and one died within four days of starting treatment. Complete remission was achieved in three patients, but only patient 8 has survived, following chemotherapy and unrelated donor bone marrow transplant. Details of this infant and her treatment have already been published. ${ }^{2}$ Patient 5 relapsed and died of leukaemia and patient 9 died in first remission from pulmonary complications of respiratory syncytial virus pneumonitis. This group is too small to provide meaningful survival data beyond documenting prolonged survival and possible cure in one patient. All patients with TMD have survived, although patient 6 with Down's syndrome subsequently developed AML, which responded successfully to standard treatment.

\section{DISCUSSION}

The chief value of this report is the documentation of the incidence of congenital acute leukaemia in a predominantly northern European population, rather than providing a review of current literature, ably carried out in two recent reviews, ${ }^{13}$ or defining a plan of management. It seemed sensible to relate the incidence to numbers of live births rather than to any particular age defined population. It confirms the rarity of this condition revealed in the recent Dutch series, ${ }^{3}$ although incidence rates were not calculated in that report. The long gaps between cases and the illusion of clustering in time in the current series almost certainly reflect chance occurrence in a very rare condition.
Our categorisation of five cases as congenital leukaemia could be challenged. One infant with Down's syndrome (patient 2), who died aged 1 day, might have had a pathological process indistinguishable from typical TMD apart from the fatal outcome. Such an outcome does not in itself preclude TMD. Another infant (patient 5) who presented at age 88 days could justifiably have been classed as having classic infantile ALL, even though, as in many other cases of infantile ALL, the leukaemic process must have started before birth. This case was included only because of the necessarily arbitrary time limit of 3 months from birth that we used to identify our cases of congenital leukaemia. Had we restricted ourselves to cases diagnosed within 4 weeks of birth, as done by others, ${ }^{3}$ one further patient with null ALL (patient 9), one with AML (patient 1), and one with TMD (patient 6), who presented because of an incidental blood count performed before cardiac surgery, would have been excluded from our study. This would leave only patients 2 and 8 , in both of whom leukaemia was present at birth. Therefore, it is possible that a more realistic incidence of congenital acute leukaemia could be less than half the figure that we have calculated. Any age limit used to define congenital leukaemia, other than diagnosis at birth, remains arbitrary. A case could be made that the very concept of congenital leukaemia is in itself artificial and unhelpful.

\footnotetext{
"By the judicious use of an aggressive approach to treatment, which may need to be individually tailored to each infant's disease and clinical circumstances, cure may even be achieved"
} 


\section{Take home messages}

- Congenital acute leukaemia is extremely rare-its incidence was $8.6 / 10^{6}$ live births/year, and would be less than half this value if only patients presenting within 4 weeks of birth were counted

- One patient, who presented at birth, remains well five years after diagnosis

- Four infants with transient myeloproliferative disorder (TMD) were also identified, all of whom had trisomy 21 , either as Down's syndrome or restricted to proliferating marrow cells

- All four patients with TMD survive

There can be no doubt about the transient nature of the disease in those who we classified as having TMD. However, the fact that TMD remains a retrospective diagnosis that is essentially conditional upon demonstrating its transient nature means that the true biological nature of affected patients who die may remain obscure. Because of variations in the index of suspicion among different paediatricians and haematologists, coupled with the probable spontaneous recovery of unrecognised affected patients (as would have been the case in patient 6 had she not had heart disease), a meaningful incidence of TMD cannot be calculated from our study. It is probably higher than we have observed. Despite the recent publication of frequent mutations in the GATA- 1 gene in TMD (and acute megakaryoblastic leukaemia) in children with Down's syndrome and even in a pair of twins with acquired trisomy $21,{ }^{4}$ there is as yet no robust, validated, objective, diagnostic feature that can distinguish between TMD and true leukaemia, or forecast which children with TMD will subsequently develop leukaemia, although considerable efforts have been made to apply the range of available clinical and laboratory features to this end. ${ }^{3}$ A putative leukaemia gene has long been suggested, located on chromosome $21,{ }^{5}$ but how trisomy 21 interacts with the mutated GATA-1 gene remains unknown. We found evidence of trisomy 21 in all four patients who we diagnosed with TMD, including one (patient 4) in whom subsequently we found no clinical or cytogenetic evidence of Down's syndrome. The clinical behaviour of this last patient is not unique.

Some inferences can be drawn from the observed behaviour and response to treatment. From a practical point of view, recognition of the clinical features of Down's syndrome and/or finding trisomy 21 in either all or a proportion of bone marrow cells of patients with putative congenital leukaemia should encourage caution. If possible, a course of observation in such patients is reasonable on the grounds that TMD remains a distinct possibility. If the clinical situation were to deteriorate, minimal therapeutic intervention, such as very small doses of cytarabine, as used in our study, may help to buy time, even in patients with true acute leukaemia. Our findings reinforce an emerging consensus for a "watch and wait" policy. ${ }^{13}$ Equally, given the almost inevitably poor outcome for untreated infants with true acute leukaemia, it is reasonable to consider some form of intervention. Our results confirm that remission may be achieved in some infants. They also support the possibility that by the judicious use of an aggressive approach to treatment, which may need to be individually tailored to each infant's disease and clinical circumstances, cure may even be achieved. Together with the Dutch cases, ${ }^{3}$ and restricting the definition to leukaemia presenting within the first 4 weeks of life, these two population based studies have resulted in 17 patients, six of whom went into remission and three of whom are potentially cured, remaining alive and well 25, six, and five years after diagnosis, respectively. However, to gain a realistic view of the efficacy of different approaches, prospective international studies of putative congenital leukaemia are required. It seems too rare a condition for individual centres to make therapeutic progress, and it remains possible that the demographic and clinical features of congenital leukaemia (and TMD) vary among different geographically defined populations.

\section{ACKNOWLEDGEMENTS}

The authors thank Dr G Summerfield and Dr M Abela for providing clinical details on patients 1 and 2, respectively.

\section{Authors' affiliations}

R P S Bajwa, R Skinner, K P Windebank, Department of Paediatric Oncology, Royal Victoria Infirmary, Newcastle upon Tyne NE1 4LP, UK M M Reid, Department of Haematology, Royal Victoria Infirmary

\section{REFERENCES}

1 Lange $\mathbf{B}$. The management of neoplastic disorders of haemopoiesis in children with Down's syndrome. Br J Haematol 2000;1 10:512-24.

2 Baiwa R, Skinner R, Windebank KP, et al. Chemotherapy and marrow transplantation for congenital leukaemia. Arch Dis Child Fetal Neonatal Ed 2001;84:F47-8.

3 Bresters D, Reus ACW, Veerman AJP, et al. Congenital leukaemia: the Dutch experience and review of the literature. Br J Haematol 2002;117:513-24.

4 Rainis L, Bercovich D, Strehl S, et al. Mutations in exon 2 of GATA-1 are early events in megakaryocytic malignancies associated with trisomy 21 . Blood 2003; 102:981-6.

5 Abe K, Kajii T, Niikawa N. Disomic homozygosity in 21 trisomic cells: a mechanism for transient myeloproliferative syndrome. Hum Genet 1989;82:313-6. 